\title{
Occlusion in Implant Dentistry-Issues and Considerations
}

\author{
Dhanasekar B', Aparna IN², Neha Mall ${ }^{3}$, Amit Garg ${ }^{4}$
}

\begin{abstract}
The goal of any prosthetic procedure must include the establishment of a functional occlusion. It is known that natural teeth have periodontal ligament receptors that protect the teeth from excessive occlusal forces, which can cause trauma to supporting tissues and bone. Although many factors are involved in the neuro-muscular reex actions in natural teeth, there are no specic defense mechanisms against occlusal forces in implant-supported prosthesis. Complications (prosthetic or bony support) reported in follow-up studies underline occlusion as one of the determining factors for success or failure of implants.
\end{abstract}

Keywords: Implant protective occlusion, Occlusion, Occlusal schemes.

${ }^{1}$ Associate Professor

Department of Prosthodontics

Manipal College of Dental Sciences

Manipal, Karnataka, India

${ }^{2}$ Professor and Head

Department of Prosthodontics

Manipal College of Dental Sciences

Manipal, Karnataka, India.

${ }^{3}$ Senior Lecturer

Department of Prosthodontics

JCD Dental College

Sirsa, Haryana, India

${ }^{4}$ Reader,

Department of Periodontics,

JCD Dental College

Sirsa, Haryana, India.

\section{INTRODUCTION}

D ue to absence of periodontal liga ment, osseointegrated implants, unlike natural teeth, react biomechanically in a dissimilar fashion to occlusal force. It is therefore believed that dental implants may be more prone to occlusal overloading, which is often regarded as one of the potential causes for peri-implant bone loss and failure of the implant/ implant prosthesis. It needs to be stressed that occlusal overload can cause mechanical and clinical complications on dental im- plants and implant prostheses such as screw loosening, screw fracture, fracture of veneering material, prosthesis fracture, and continual marginal bone loss, implant fracture and even implant loss.

\section{DIFFERENCES BETWEEN TEETH AND IMPLANTS (TABLE 1)}

The fundamental, inherent difference between the tooth and implant is that an endosseous implant is in direct contact with the bone while a natural tooth is suspended by periodontal ligament (PDL). The pres-

\begin{tabular}{|c|c|c|}
\hline Connection & $\begin{array}{l}\text { Tooth } \\
\text { Periodontal ligament }\end{array}$ & $\begin{array}{l}\text { Implant } \\
\text { Osseointegration } \\
\text { functional ankylosis }\end{array}$ \\
\hline Mobility & $\begin{array}{l}\text { Variable (anterior teeth } \\
\text { more than posterior) }\end{array}$ & None \\
\hline Proprioception & PDL mechanoreceptors & Osseoperception \\
\hline $\begin{array}{l}\text { Movement } \\
\text { Apical } \\
\text { Lateral }\end{array}$ & $\begin{array}{l}\text { Initially } 28 \mu \mathrm{m} \\
56-108 \mu \mathrm{m}\end{array}$ & $\begin{array}{l}\text { No initial movement } \\
10-50 \mu \mathrm{m}\end{array}$ \\
\hline Fulcrum to lateral force & Apical $3^{\text {rd }}$ of root & Crestal bone \\
\hline Cross section & Not round & Usually round \\
\hline Diameter & Larger & Narrow \\
\hline Overloading & $\begin{array}{l}\text { Wear facets, abfraction, } \\
\text { cold sensitivity }\end{array}$ & $\begin{array}{l}\text { Screw loosening, } \\
\text { screw fracture, } \\
\text { prosthesis fracture }\end{array}$ \\
\hline
\end{tabular}


ence of PDL around natural teeth acts as a viscoelastic shock absorber and significantly reduces the amount of stress transmitted to the bone, especially at the crestal region (1). Compared with a tooth, the direct bone interface with implant is not as resilient, so the energy imparted by an occlusal force is not dissipated partially but rather transmits a higher intensity force to the contiguous bone.

The mean values of axial displacement of teeth in the socket are $25-100 \mu \mathrm{m}$, whereas the range of motion of osseointegrated dental implants has been reported approximately $3-5 \mu \mathrm{m}(2,3)$. PDL is functionally oriented toward an axial load, which leads to the physiological-functional adjustment of occlusal stress along the vertical axis of the tooth and periodontal-functional adaptability to changing stress conditions (4). Furthermore, the tooth mobility from PDL can provide adaptability to jaw skeletal deformation or torsion in natural teeth (3). However, dental implants do not possess those advantages due to the lack of PDL. Upon load, the movement of a natural tooth begins with the initial phase of periodontal compliance that is primarily nonlinear and complex, followed by the secondary movement phase occurring with the engagement of the alveolar bone (2). In contrast, a loaded implant initially deflects in a linear and elastic pattern, and the movement of the implant under load is dependent on elastic deformation of the bone. To accommodate the disadvantageous kinetics associated with dental implants, gradient loading was suggested $(3,5)$.

A natural tooth moves rapidly 56-108 $\mu \mathrm{m}$ and rotates at the apical third of the root upon a lateral load (6), and the lateral force on the tooth is diminished immediately from the crest of bone along the root (1). On the other hand, implant does not exhibit a primary immediate movement but a secondary movement occurs gradually, reaching up to about $10-50 \mu \mathrm{m}$ under a similar lateral load which is related to the viscoelastic bone movement. In addition, there is a concentration of greater forces at the crest of surrounding bone of dental implants without any rotation of implants $(2,7)$. A transverse load and clenching at centric contacts results in highest stresses in the crestal bone.

The width of almost every natural tooth is greater than the width of the implant used to replace the tooth. The greater the width of a transosteal structure, the lesser the magnitude of stress transmitted to the surrounding bone. The cross sectional shape of the natural tooth at the crest is biomechanically optimized to resist lateral loads, implants however are almost round in cross section, which is less effective in resisting lateral bending loads thereby concentrating loads in the crestal region (8). In addition, the size of implant is decided by existing bone volume rather than amount and direction of forces.

The elastic modulus of tooth is closest to bone compared to the available implant biomaterials. Hence under similar loading conditions, implant generates greater stresses and strain at the crest of bone than natural tooth.

The precursor signs of a premature contact or occlusal trauma on natural teeth are reversible and include hyperemia and occlusal or cold sensitivity (9) which do not occur with endosteal implants. The magnitude of stress may cause bone microfractures, which place the surrounding bone in pathologic loading zone causing bone loss and may lead to mechanical failure of prosthetic or implant components (10).

In natural teeth, PDL has neuro-physiological receptor functions, which transmit information of nerve endings with corresponding reflex control to the central nervous system. The presence or absence of the PDL receptor function makes a remarkable difference in detecting early phase of occlusal force between teeth and implants. Jacobs and van Steenberghe $(11,12)$ evaluated occlusal awareness by the perception of an interference and reported that when teeth oppose each other, an interference is perceived at approximately $20 \mu \mathrm{m}$. An implant opposing a natural tooth detects in- terference at $48 \mu \mathrm{m}$ and opposing implant interference is perceived at $64 \mu \mathrm{m}$. However, when tooth opposes implant overdenture, the awareness is at $108 \mu \mathrm{m}$. Because of the decreased occlusal awareness of implants, adaptive responses like deviation from arc of closure, closure in a position other than centric occlusion is not perceived. Moreover, the premature contacts are often on smaller areas and on inclines of the posterior teeth, therefore a greater angled stress is generated to implant-bone interface.

Clinical evidence of occlusal trauma on natural teeth includes enamel wear facets, stress line, cervical abfraction including an overall increase in periodontal membrane thickness, increased radio opacity around teeth as observed in radiographs. These signs are rarely seen in the implant prosthesis, thus fewer signs are present to warn the practitioner to reduce the stress on the support system.

It can be speculated that osseointegrated implants without periodontal receptors would be more susceptible to occlusal overloading because the load sharing ability, adaptation to occlusal force and mechanoperception are significantly reduced in dental implants.

\section{OVERLOADING FACTORS OF IM- PLANT OCCLUSION (FIGURE 1)}

The occlusal forces generated are influenced by parafunction, masticatory dynamics, tongue size, implant arch position and location. A large cantilever of an implant prosthesis can generate overloading, possibly resulting in peri-implant bone loss and prosthetic failures $(13,14,15)$. When a biting force is applied to the distal cantilever, the highest axial force and bending moments are recorded on the distal implants, which are more pronounced in the prostheses supported by only three implants as compared with prostheses with five or six implants. In a series of studies, it was found that closing and chewing forces increased distally along the cantilever beams when occluding with complete denture and decreased distally when occluding with fixed partial denture $(16,17)$. The displacement of complete denture during func- 


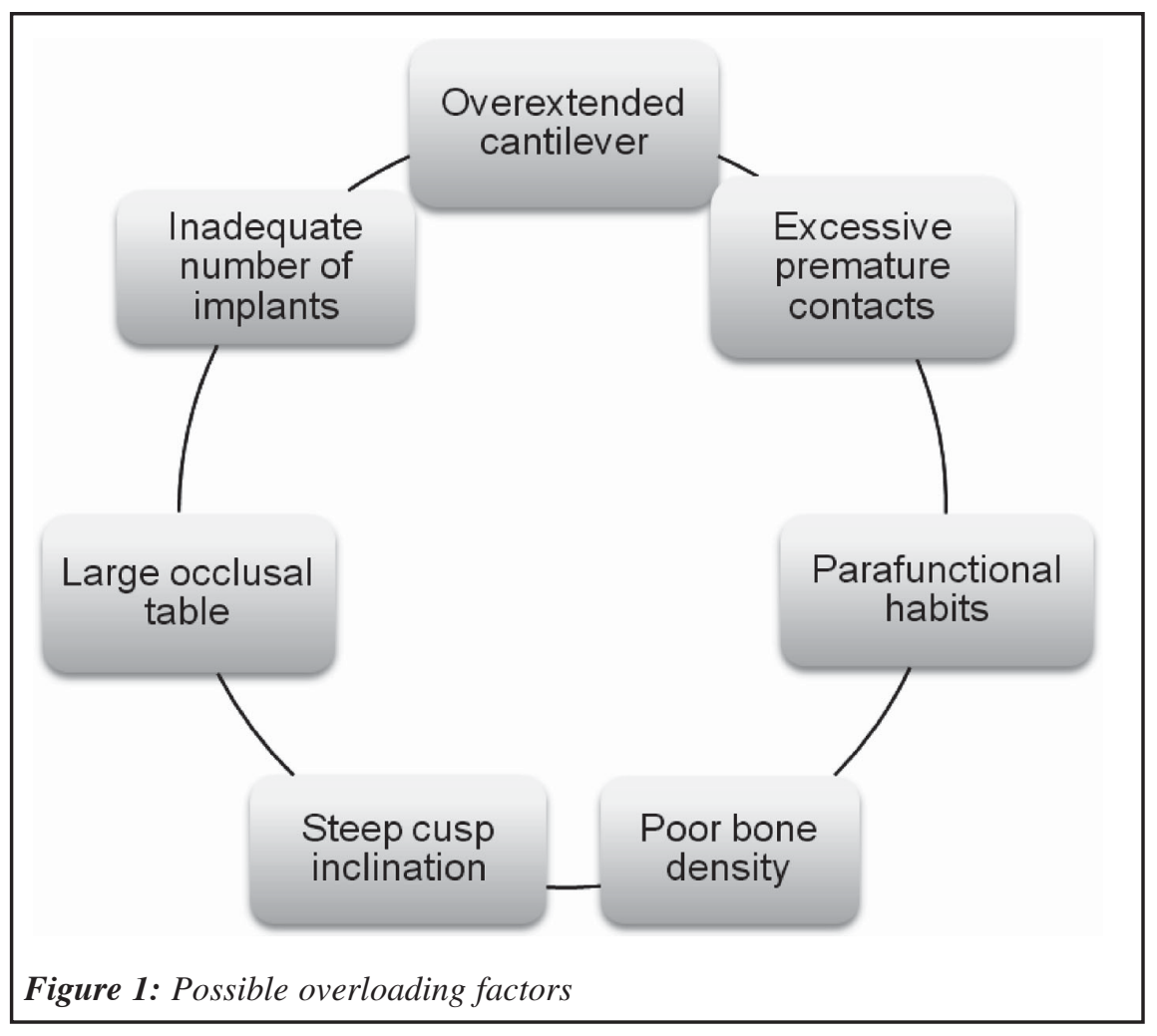

tion might create heavy occlusal contacts on the posterior cantilever segment. This finding suggested that simultaneous occlusal contacts along the prosthesis were significant, and the number and distribution of occlusal contacts on cantilever segments should be controlled carefully with the opposing complete denture. Regarding a cantilever length, a clinical study demonstrated that long cantilevers $(15 \mathrm{~mm})$ in- duced more implant-prosthesis failures as compared with cantilevers shorter than $15 \mathrm{~mm}$, (15) this is particularly critical for the prosthesis supported by less number of implants.

Parafunctional activities (bruxism, clenching, etc.) and improper occlusal designs are correlated with implant bone loss/failure, implant fractures, and prosthesis failures.

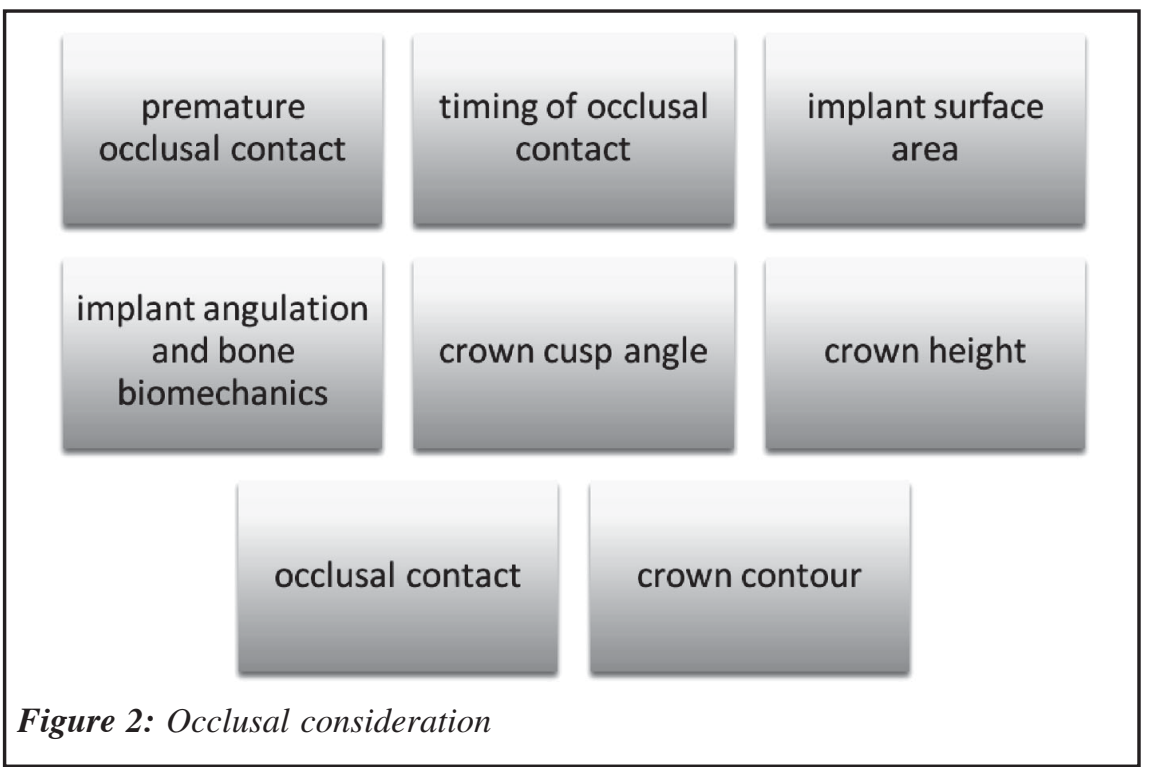

Falket al (17) reported that the occlusal design (the number and distribution of occlusal contacts) had a major influence on the different force distribution between a cantilever segment and implant-supported area, increasing local forces significantly on the cantilever unit. It is implied that heavy occlusal force and undesirable distribution of occlusal contacts may be factors of overloading, thus possibly leading to higher susceptibility to implant bone loss, implant fractures/loss, and prosthesis failures.

Bone quality has been considered the most critical factor for implant success at both surgical and functional stages, and it is therefore suggested that occlusal overload in poor-quality bone can be a clinical concern for implant longevity $(18,19)$.

Mischet al. (20) proposed that progressive bone loading can permit development time for load-bearing bone at bone-to-implant interface and provide bone with adaptability to loading via a gradual enhancement of loading. He further described that the progressive bone loading could be attained by the practice of increasing occlusal load over a time period of 6 months. Appletonet al (21) also noted that progressively loaded implants had increased bone density as well as reduced amounts of crestal bone loss. These findings suggest that extended healing time and carefully monitored loading may be needed in poor quality bone.

\section{OCCLUSAL CONSIDERATIONS FOR IMPLANT PROSTHESIS (FIGURE 2) Premature occlusal contacts}

No occlusal contacts should be premature during maximum intercuspation and centric occlusion, especially in implant supported prosthesis.

\section{Timing of occlusal contacts}

Due to initial difference in vertical movement of natural tooth and implant, the initial occlusal contact should account for this difference or else the implants will sustain greater loads than the adjacent teeth. Occlusion should be evaluated for any pre maturities prior to implant reconstruction and these should be corrected. For initial 
implant occlusal adjustment in centric occlusion, thin articulating paper (less than $25 \mu \mathrm{m}$ ) is used under light tapping force. The implant prosthesis should barely contact and the adjacent teeth should exhibit greater initial contacts. Once the equilibration with light force is completed, heavier occlusal forces should be applied in which there should be similar intensity of contacts on implant crown and adjacent teeth thereby sharing the load equally (19). Complete arch implant supported prosthesis in one or both arches does not require a difference in a light and heavy occlusal forces. Anterior teeth exhibit greater apical and lateral movements; therefore the occlusal adjustment in this direction is more critical to implant success and survival.

\section{Influence of surface area}

Mechanical stress is defined as the force magnitude divided by the cross sectional area over which that force is applied Wider implants have greater area of bone contact at the crest compared to narrower implant, thus reducing the mechanical stresses. Stress and strain magnitude can also be reduced by placing additional implants in the region of concern or splinting the implant crowns to increase the area of support. $(22,23)$

\section{Implant body orientation and bone mechanics}

Implants are designed for long axis load which generates greater proportion of compressive stress than tension or shear stress. It has been reported that cortical bone is strongest in compression, 30\% weaker in tension and $65 \%$ weaker in shear stress (24). Occlusal load applied at an angle increases the magnitude of shear stress on the implant which subsequently affects the physiologic limit of compressive and tensile stress on bone thereby reducing the strength of bone. Therefore primary component of occlusal load should be directed along the long axis of implant body, not at an angle or following the angulation of an abutment post. Angled abutment should be used only to improve the path of insertion of prosthesis or for esthetic results.

\section{Crown cusp angle}

Developing tooth morphology to induce axial loading is an important factor to consider when constructing implant prostheses. Weinberg (25) claimed that cusp inclination is one of the most significant factors in the production of bending moment. The reduction of cusp inclination can decrease the resultant bending moment with a lever-arm reduction and improvement of axial loading force.

\section{Crown height}

The implant crown height is often longer than the original anatomical crown, even in Division A bone. Crown height with a lateral load may act as a vertical cantilever and a magnifier of stress at the implant to bone interface (19).

\section{Occlusal contact position}

The ideal primary occlusal contacts in implant prosthesis will reside within the diameter of the implant within the central fossa. Secondary occlusal contact should remain within $1 \mathrm{~mm}$ of the periphery of the implant to decrease moment loads. Marginal ridge contacts should be avoided as these may be the most damaging as these create cantilever effects and bending moments.

\section{Implant crown contour}

Once the teeth are lost, edentulous ridge resorbs in a medial direction for maxilla and lingually for mandibular arch, therefore endosteal implants are usually placed more lingual than their natural predecessors. The diameter and distribution of implants and harmonization to natural teeth are important factors to consider when deciding the size of an occlusal table. A narrow occlusal table reduces the chance of offset loading and increases axial loading, which eventually can decrease the bending moment $(19,26)$.

In Division A maxillary ridge, implant can be placed under the central fossa region, here mandibular buccal cusp is the dominant occluding cusp. The facial cusp of maxillary crown should remain similar to the original tooth for proper esthetics but should remain out of occlusal contact. With further resorption of maxillary arch to Division B, C, D bone the maxillary palatal cusp becomes the primary contact area. In mandibular Division A bone, the implant is located under the central fossa, whereas in Division B, the implant is located under the lingual cusp region of preexisting natural tooth. The lingual contour of mandibular implant crown is usually kept similar to original natural dentition to prevent tongue biting during function. However, no occlusal contacts occur on lingual cusp. The buccal contours of the crown are contoured to reduce the occlusal table and offset loads on the implant.

\section{TYPES AND PRINCIPLES OF IMPLANT OCCLUSION}

The primary goal of an occlusal scheme is to maintain the occlusal load that has been transferred to implant body within the physiologic limits of each patient. The types and basic principles of implant occlusion have largely been derived from occlusal principles in tooth restoration. Three occlusal concepts (balanced, group function, and mutually protected occlusion) have been established throughout clinical trials and conceptual theories $(27,28,29)$.

Bilateral balanced occlusion has all teeth contacting during all excursions. It is primarily used in complete denture fabrication (30). In group-function occlusion, posterior teeth contact on the working side during lateral movements, without balancing side contacts. This occlusion is used primarily with compromised canines in order to share lateral pressures to posterior teeth instead of the canine (31). Mutually protected occlusion has posterior teeth protection in habitual and/ or centric occlusion via posterior contacts in maximum intercuspation (MIP), while light contacts on anterior teeth and anterior guidance during all excursions. This occlusal scheme is based on the concept that the canine is a key element of occlusion avoiding heavy lateral pressures on posterior teeth (32).

Implant-protected occlusion has been proposed strictly for implant prostheses (8). This concept is designed to reduce occlusal force on implant prostheses and thus to protect implants. For this, several modifi- 
cations from conventional occlusal concepts have been proposed, which include providing load sharing occlusal contacts, modifications of the occlusal table and anatomy, correction of load direction, increasing of implant surface areas, and elimination or reduction of occlusal contacts in implants with unfavorable biomechanics. Also, occlusal morphology guiding occlusal force to the apical direction, utilization of crossbite occlusion, a narrowed occlusal table, reduced cusp inclination, and a reduced length of cantilever in mesio-distal and bucco-lingual dimension have all been suggested as factors to consider when establishing implant occlusion (33).

\section{BASIC PRINCIPLES OF IMPLANT} OCCLUSION MAY INCLUDE

- Bilateral stability in centric (habitual) occlusion,

- Evenly distributed occlusal contacts and force,

- No interferences between retruded position and centric (habitual) position,

- Wide freedom in centric (habitual) occlusion,

- Anterior guidance whenever possible,

- Smooth, even, lateral excursive movements without working/non-working interferences.

Along with evenly distributed occlusal contacts, bilateral occlusal stability provides stability of the masticatory system and a proper force distribution (34). The axial loading on threaded implants can be distributed well along the implant-bone interface, and the cortical bone can resist the compressive stress favorably. A flat area around centric contacts can direct the occlusal force in an apical direction (26). Force distribution between implants and natural teeth in a partially edentulous region can be accomplished with serial and gradient occlusal adjustments (35). Due to the non-significant mobility during initial tooth movement, implants may absorb all heavy biting force because natural teeth can be intruded easily with any occlusal force. Mischet al. $(19,20)$ proposed that occlusal adjustments could be performed by the elimination of mobility difference between implants and teeth under heavy oc- clusion. This approach may evenly distribute loads between implants and teeth. Over the years, natural teeth have positional changes in vertical and mesial direction while implants do not change their positions. In addition, enamel on the tooth wears more than porcelain on implant restorations. The positional changes of teeth may intensify the occlusal stress on implants. In order to prevent the potential overloading on implants from the positional changes, reevaluation and periodic occlusal adjustments are imperative $(19,26,36)$.

\section{CLINICAL APPLICATIONS Occlusion on full-arch fixed pros- theses}

For full-arch fixed implant prostheses, bilateral balanced occlusion has been successfully utilized for an opposing complete denture, while group-function occlusion has been widely adopted for opposing natural dentition. Mutually protected occlusion with a shallow anterior guidance was also recommended for opposing natural dentition (29,33). Bilateral and anteriorposterior simultaneous contacts in centric relation and MIP should be obtained to evenly distribute occlusal force during excursions regardless of the occlusal scheme. In addition, smooth, even, lateral excursive movement without working/nonworking occlusal contacts on cantilever should be obtained. When a cantilever is utilized in full-arch fixed implant prosthesis, infraocclusion on a cantilever unit is suggested to reduce fatigue and technical failure of the prosthesis.

\section{Occlusion on overdentures}

For the occlusion on overdentures, it has been suggested to use bilateral balanced occlusion with lingualized occlusion on a normal ridge. On the other hand, monoplane occlusion was recommended for a severely resorbed ridge.

Wennerberg and Jemt (37) described that additional implants in the maxilla could provide tripodism to reduce overloading and clinical complications. Also, axial positioning and reduced distance between posterior implants are important factors to decrease overloading (38). The utilization of cross-bite occlusion with palatally placed posterior maxillary implants can reduce the buccal cantilever and improve the axial loading $(19,25)$.

\section{Occlusion on posterior fixed pros- theses}

Anterior guidance in excursions and initial occlusal contact on natural dentition will reduce the potential lateral force on osseointegrated implants. Group-function occlusion should be utilized only when anterior teeth are periodontally compromised $(8,29,33)$. During lateral excursions, working and non-working interferences should be avoided in posterior restorations (35). Moreover, reduced inclination of cusps, centrally oriented contacts with a $1-$ $1.5 \mathrm{~mm}$ flat area, a narrowed occlusal table, and elimination of cantilevers have been proposed as key factors to control bend overload in posterior restorations.

\section{Occlusion on single implant pros- thesis}

Anterior and lateral guidance should be obtained in natural dentition; in addition, working and non-working contacts should be avoided in a single restoration (39). Light contacts at heavy bite and no contact at light bite in MIP are considered a reasonable approach to distribute the occlusal force on teeth and implants. Two implants for a single molar have been utilized and demonstrated less screw loosening and higher success rates (40). However, the placement of two implants in a limited space is a challenging procedure, and difficulty in oral hygiene and prosthetic fabrication may be encountered. Instead of two implants in a single molar area, a wide-diameter implant ideally positioned and axis in a molar area could be a better option to reduce surgical and prosthetic difficulties and to improve oral hygiene and loading conditions.

\section{CONCLUSION}

The objectives of implant occlusion are to minimize overload on the bone-implant interface and implant prosthesis, to maintain implant load within the physiological limits of individualized occlusion, and finally to provide long-term stability of implants and implant prostheses. To accomplish these objectives, increased support 
area, improved force direction, and reduced force magnification are indispensable factors in implant occlusion. In addition, systematic, individualized treatment plans and precise surgical/ prosthodontic procedures based on biomechanical principles are prerequisites for optimal implant occlusion. Implant occlusion should be re-evaluated and adjusted periodically to prevent them from developing potential overloading clinical sequelae, thus providing implant longevity.

\section{REFERENCES}

1. Hillam DG. Stresses in the periodontal ligament. J Periodontal Res 1973;8:5156.

2. Sekine $\mathrm{H}$, Komiyama $\mathrm{Y}$, Hotta $\mathrm{H}$, Yoshida K. Mobility characteristics and tactile sensitivity of osseointegrated fixturesupporting systems. In:vanSteenberghe, D., eds. Tissue integration in oral maxillofacial reconstruction: Amsterdam Excerpta Medica 1986:p326-32.

3. Schulte W. Implants and the periodontium. Int Dent J 1995;45:16-26.

4. Lindhe $\mathrm{J}$, Karring $\mathrm{T}$. Anatomy of periodontium. In: Lindhe J, Karring T and Lang NP. Clinical periodontology and implant dentistry. $3^{\text {rd }}$ ed. Copenhagen: Munksgaaard 1998:p45-49.

5. Misch CE. Occlusal considerations for Implant supported prostheses. In: Misch CE. eds. Contemporary implant dentistry St.Louis: Mosby 1993:p705-33.

6. Partt GJ. Measurement of physiological mobility of individual teeth in an axial direction. J Dent Res 1960;39:608-18.

7. Richter EJ. In vivo horizontal bending moments on implants. Int $J$ Oral Maxillofac Implants 1998;13:232-44

8. Bidez MW, Micsh CE. Force transfer in implant dentistry: basic concepts and principles. J Oral Implantol 1992;18:26474.

9. Glickman I. Inflammation and trauma from occlusion: Co-destructive factors in periodontal disease. J Periodontol 1963;34:5-10.

10. Frost HM. Bone "mass" and the mechanostat: a proposal. Anat Rec 1987;219:1-9.

11. Jacobs $R$, van Steenberghe $D$. Comparative evaluation of oral tactile function by means of teeth or implant support prostheses. Clin Oral Implant Res 1991;2:75-80.

12. Jacobs $R$, van Steenberghe $D$. Comparison between implant supported prosthesis and teeth regarding passive threshold level. Int J Oral Maxillofac Implants 1993;8:549-54.
13. Lindquist LW, Rockler B, Carlsson GE. Bone resorption around fixtures in edentulous patients treated with mandibular fixed tissue-integrated prostheses. J Prosthet Dent 1988; 59:59-63.

14. Quirynen M, Naert I, van Steenberghe D. Fixture design and overload inuence marginal bone loss and fixture success in the Branemark system. Clin Oral Implants Res 1992;3:104-11.

15. Shackleton JL, Carr L, Slabbert JC, Becker PJ. Survival of fixed implantsupported Prostheses related to cantilever lengths. J Prosthet Dent 1994; 71:23-26.

16. Falk H, Laurell L, Lundgren D. Occlusal Force pattern in dentitions with mandibular implant-supported fixed cantilever prostheses occluded with complete dentures. Int J Oral Maxillofac Implants 1989;4:55-62.

17. Falk H, Laurell L, Lundgren D. Occlusal Interferences and cantilever joint stress in implant-supported prostheses occluding with complete dentures. Int $J$ Oral Maxillofac Implants 1990;5:70-77.

18. Lekolm U, Zarb GA. Patient selection and preparation. In: Branemark PI, Zarb GA and Albrektsson T. eds. Tissueintegrated prostheses. Chicago, London, Berlin, Rio de Janeiro, Tokyo: Quintessence Publishing Company 1985:p199-210.

19. Misch CE. Occlusal considerations of implant supported prosthese. In:Misch CE. eds. Contemporary implant dentistry. $2^{\text {nd }}$ ed. St.Louis: Mosby 1999:p609-28.

20. Misch CE. Endosteal implants for posterior single tooth replacement: alternatives, indications, contraindications, and limitations. J Oral Implantol 1999;25:80-94.

21. Appleton RS, Nummikoski PV, Pigmo MA, Bell FA, Cronin RJ. Peri-implant bone changes in response to progressive osseous loading. J Dent Res 1997;76 (special issue): 412 .

22. Ranger B, Krogh $\mathrm{PH}$, Langer B, et al. Bending overload and implant fracture: a retrospective clinical analysis. Int $J$ Oral Maxillofac Implants 1995;7:40-44.

23. Akca K, Iplikcioglu H. Finite element stress analysis of the effect of short implant usage in place of cantilever extensions in mandibular posterior edentulism. J Oral Rehab 2002;29:350-56.

24. Reilly DT, Burstein AH. The elastic and ultimate properties of compact bone tissue. J Biomech 1975;80:393-405.

25. Weinberg LA. Reduction of implant loading with therapeutic biomechanics. Implant Dent 1998;7:277-85.

26. Rangert BR, Sullivan RM, Jemt TM. Load factor control for implants in the posterior partially edentulous segment. Int $J$ Oral Maxillofac Implants 1997;12:360-70.

27. Pameijer JHN. Occlusion: Periodontal and occlusal factors in crown and bridge procedures. Amsterdam: Dental Center for Postgraduate Courses 1985:85.

28. Santos J. Concepts of occlusion. In: Occlusion: principles and concepts. St.Louis, Tokyo: Ishiyaku Euro America, Inc 1985:p179-90.

29. Hobo S, Ichida E, Garcia LT. Ideal occlusion. In: Osseointegration and occlusal rehabilitation. Tokyo, Berlin, Chicago, London, SaoPaulo, HongKong: Quintessence Publishing Company 1989:p315-28.

30. Stuart CE. Articulation of human teeth. In: Collum BB and Stuart CE eds. South Pasadana, CA: Scientic press; 1955: p91-123.

31. Schuyler $\mathrm{CH}$. Considerations of occlusion in fixxed partial dentures. Dent Clin North Am 1959;37:175-85.

32. D'Amico A. The canine teeth: normalfunctional relation of the natural teeth of man. J South California Dent Assoc 1958;26:1-7.

33. Chapman RJ. Principles of occlusion for implant prostheses: guidelines for position, timing, and force of occlusal contacts. Quintessence Int 1989; 20:473-80.

34. Beyron HL. Optimal occlusion. Dental Clinics of North America 1969;37:53754.

35. Lundgren D, Laurell L. Biomechanical aspects of fixed bridge work supported by natural teeth and endosseous implants. Periodontology 2000 1994; 4:23-40.

36. Dario LJ. How occlusal forces change in implant patients: a clinical research report. J Am Dent Assoc 1995;126:1130-33.

37. Wennerberg A, Jemt T. Complications in partially edentulous implant patients: a 5year retrospective follow-up study of 133 patients supplied with unilateral maxillary prostheses. Clin Implant Dent Related Res 1999;1:49-56.

38. Belser UC, Mericske-Stern R, Bernard JP, Taylor TD. Prosthetic management of the partially dentate patient with fixed implant restorations. Clin Oral Implant Res 2000;11 Suppl 1:126-45.

39. Engelman MJ. Occlusion. In: eds Clinical decision making and treatment planning in osseointegration. Chicago: Quintessence Publishing Co; 1996:p169-76.

40. Balshi TJ, Hernandez RE, Pryszlak MC, Rangert B. A comparative study of one implant vs. two replacing a single molar. Int J Oral Maxillofac Implants 1996; 11:372-78. 